\title{
Predicted Steady State Volume of Distribution at Terminal Phase
}

National Cancer Institute

\section{Source}

National Cancer Institute. Predicted Steady State Volume of Distribution at Terminal

Phase. NCI Thesaurus. Code C85795.

The volume of distribution of the terminal phase at steady state based on the predicted last concentration. 